\title{
Design of Blue Pottery Working Table for Indian Population Using Taguchi Approach
}

\author{
Awadhesh Kumar ${ }^{1}$, Monica Sharma1, Govind Sharan Dangayach ${ }^{2}$, Anand Kumar K ${ }^{2}$ \\ ${ }^{1}$ Malaviya National Institute of Technology \\ J.L.N Marg, Jaipur India \\ akbhardwaj.mech@mnit.ac.in; msharma.dms@mnit.ac.in \\ ${ }^{2}$ Malaviya National Institute of Technology \\ J.L.N Marg, Jaipur India \\ gsdangayach.mech@mnit.ac.in \\ anandkumarvamsi@gmail.com
}

\begin{abstract}
Blue pottery has been one of the famous art of India for last five centuries. A large number of workers from blue pottery industry left their jobs because of work related problems. A significant population of the workers are working in poor postures which have high risk of Musculoskeletal disorders (MSDs) and is one of the main reason for absenteeism and leaving the profession of blue pottery manufacturing. Worker's posture can be improved by optimizing design of workstation according to their anthropometric dimensions. The aim of this paper is to optimize the design of blue pottery working table for Indian population. Taguchi Design of Experiment method is used for optimization. Height of the Table, Table width, Arm length and Shoulder height of the workers have been used as critical parameters for this purpose. Delmia V5 was used to evaluate the designed table for different Indian populations.
\end{abstract}

Keywords: Blue pottery, Workstation, Design of Experiments (DOE), Musculoskeletal disorders (MSDs)

\section{Introduction}

Blue pottery manufacturing is one of the famous art in India, very old profession employing many people. As an unorganized sector, no statistical data are available to date such as the number of people employed, accident rates, and other problems. There were four main steps involved in blue pottery manufacturing process. 1) Pottery Making 2) Designing \& Painting 3) Glazing and 4) Firing. The pottery making activity involves rolling of dough, filling the mould with rolled dough, removing unwanted dough from edges, filling it with ash which helps in retaining its shape in mould and staking it for drying and for this worker is required to work in different awkward postures as show in the Figure (1).

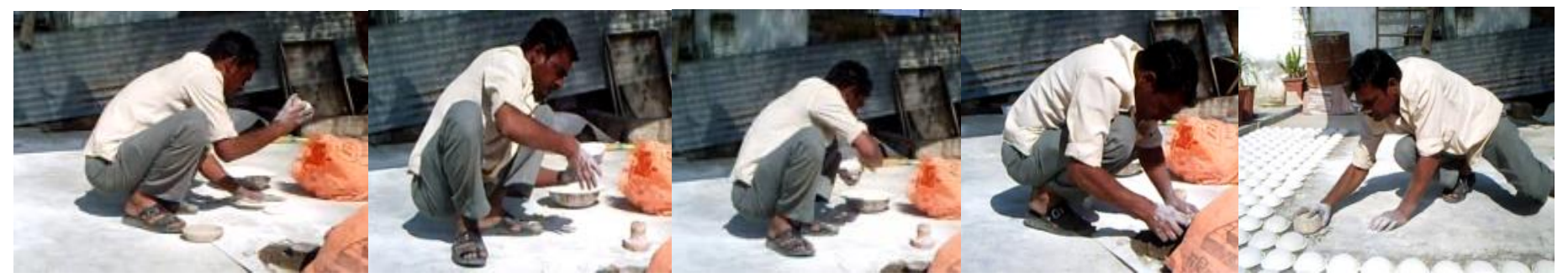

Fig. 1: Awkward postures of the workers in the pottery making.

The industrial classification of bricks, pottery, glass and cement has been identified to pose greater risk of inflammation of tendons of the hand, forearm or associated tendon sheaths [1]. Further, the awkward posture shown in Figure (1) leads to musculoskeletal disorders [2] thereby decline in productivity and quality of life [3]. Hence it is required to design a working table for this kind of activities to eliminate the awkward posture of the workers. The objective of this paper is to design a working table for blue pottery manufacturing using anthropometric analysis and taguchi approach. 


\section{Body Part Discomfort Assessment}

For this assessment 30 male workers are selected using convenient sampling. Based on the Body Part Discomfort [4] survey, the occupation related body pains experienced by the blue pottery workers were identified. According to survey there were no parts of the body that had no discomfort at all ie. all parts have been affected to some extent, low or high. Table 1 shows the list of body parts experiencing discomfort by the blue pottery workers and the percentage of those who experienced it. It was found that $100 \%$ of workers experienced the discomfort in the lower back and knee. The least experienced discomfort was pain at neck and legs, with $62.5 \%$.

Table 1: Percentage Workers Experiencing Pain.

\begin{tabular}{|l|c|c|}
\hline Body Part & $\begin{array}{l}\text { No. Of Workers With } \\
\text { Discomfort }\end{array}$ & $\begin{array}{l}\% \text { Of Workers With } \\
\text { Discomfort }\end{array}$ \\
\hline Neck & 15 & 62.5 \\
\hline Shoulders & 27 & 92.5 \\
\hline Wrist & 28 & 95 \\
\hline Elbows & 29 & 97.5 \\
\hline Forearms & 25 & 87.5 \\
\hline Upper back & 29 & 95 \\
\hline Lower back & 30 & 100 \\
\hline Knee & 30 & 100 \\
\hline Feet & 29 & 97.5 \\
\hline Leg & 06 & 40 \\
\hline
\end{tabular}

Body part discomfort survey is valuable indicator of mismatch between the task and worker [3]. Hence to fit the job to the worker, it is required to design the workstation according to the worker anthropometry.

\section{Design of working table: Taguchi approach}

For designing the working table for blue pottery workers using Taguchi approach, five levels $\left(5^{\text {th }}, 25^{\text {th }}, 50^{\text {th }}, 75^{\text {th }}\right.$ and $95^{\text {th }}$ ) of anthropometry data was used as shown in the table (2). Shoulder height, Arm length, table width and Table height are taken as the critical parameters which influence the arm reach over the working table. The modified arm reach equation [5] was used as the response equation i.e.

$$
\text { Theoretical Response, } \mathrm{R}(\mathrm{mm})=C-\sqrt{B^{2}-(A-D)^{2}}
$$

Where $\mathrm{A}=$ shoulder height, $\mathrm{B}=$ arm length, $\mathrm{C}=$ Table width and $\mathrm{D}=$ Table height. Any change in the height (eg. increase in height will result in arms raised) and width (eg. increase in width will result in bending of trunk forward) of working table will influence the efficiency. However, the effect of change in length is negligible and has not been considered as the worker can walk along the length of working table. 
Table 2: Five levels of variation in critical parameters.

\begin{tabular}{|c|c|c|c|c|c|c|}
\hline \multicolumn{2}{|c|}{ Parameters } & \multicolumn{5}{|c|}{ Levels } \\
\hline & & $\begin{array}{l}\text { L1 } \\
\%)\end{array}$ & $\begin{array}{l}\text { L2 } \\
\%)\end{array}$ & $\begin{array}{ll}\mathbf{L 3} & \left(\mathbf{5 0}^{\text {th }}\right. \\
\text { \%) }\end{array}$ & $\begin{array}{ll}\text { L4 } & \text { (75 }^{\text {th }} \\
\%) & \end{array}$ & $\begin{array}{l}\text { L5 } \quad\left(95^{\text {th }}\right. \\
\%)\end{array}$ \\
\hline Shoulder Height(A) & \multirow{4}{*}{$(\mathrm{mm})$} & 1271 & 1338 & 1381 & 1420 & 1485 \\
\hline Arm Length (B) & & 549 & 571 & 588 & 596 & 618 \\
\hline Table width (C) & & 615 & 642 & 662 & 671 & 693 \\
\hline Table Height(D) & & 920 & 978 & 1014 & 1047 & 1098 \\
\hline
\end{tabular}

Minitab-16 was used to apply the Taguchi's Design of Experiment method to analyze the working table interface. L25 orthogonal array was select by degree of freedom approach for five level and four critical control parameters with no noise level. Table 3 shows the L25 orthogonal array with theoretical response (Reach). S/N ratio is calculated even though there is no noise parameter. Table 4 shows Analysis of Variance for SN ratios to optimize the design parameters. As the goal is to minimize the response "smaller is better" signal to noise ratio is selected.

Table 3: L25 Orthogonal array indicating critical parameters and reach.

\begin{tabular}{|l|l|l|l|l|}
\hline $\begin{array}{c}\text { Shoulder } \\
\text { Height }(\mathbf{m m})\end{array}$ & Arm Length (mm) & Table Width (mm) & Table Height (mm) & Arm reach (mm) \\
\hline 1271 & 549 & 615 & 920 & 1037.14 \\
\hline 1271 & 571 & 642 & 978 & 1132.09 \\
\hline 1271 & 588 & 662 & 1014 & 1190.86 \\
\hline 1271 & 596 & 671 & 1047 & 1223.30 \\
\hline 1271 & 618 & 693 & 1098 & 1286.29 \\
\hline 1338 & 549 & 642 & 1014 & 1085.20 \\
\hline 1338 & 571 & 662 & 1047 & 1153.28 \\
\hline 1338 & 588 & 671 & 1098 & 1207.79 \\
\hline 1338 & 596 & 693 & 920 & 1117.84 \\
\hline 1338 & 618 & 615 & 978 & 1117.32 \\
\hline 1381 & 549 & 662 & 1098 & 1132.44 \\
\hline 1381 & 571 & 671 & 920 & 1007.93 \\
\hline 1381 & 588 & 693 & 978 & 1121.18 \\
\hline 1381 & 596 & 615 & 1014 & 1084.60 \\
\hline 1381 & 618 & 642 & 1047 & 1161.97 \\
\hline 1420 & 549 & 671 & 978 & 996.63 \\
\hline & & & & \\
\hline
\end{tabular}




\begin{tabular}{|l|l|l|l|l|}
\hline 1420 & 571 & 693 & 1014 & 1094.50 \\
\hline $\begin{array}{c}\text { Shoulder } \\
\text { Height (mm) }\end{array}$ & Arm Length (mm) & Table Width (mm) & Table Height (mm) & Arm reach (mm) \\
\hline 1420 & 588 & 615 & 1047 & 1069.55 \\
\hline 1420 & 596 & 642 & 1098 & 1143.53 \\
\hline 1420 & 618 & 662 & 920 & 1025.21 \\
\hline 1485 & 549 & 693 & 1047 & 1023.99 \\
\hline 1485 & 571 & 615 & 1098 & 1034.85 \\
\hline 1485 & 588 & 642 & 920 & 804.85 \\
\hline 1485 & 596 & 662 & 978 & 975.32 \\
\hline
\end{tabular}

In the Table (4), analysis of variance for SN ratios are tabulated and it is found that $\mathrm{SN}$ ratio for shoulder height and table length factors and the interaction terms are significant at an $\alpha$-level of 0.10 . For means, all the factors and the interaction terms are significant at an $\alpha$-level of 0.10. Figure (2) and Figure (3) shows the Main Effect Plot for SN ratios and main effect plot for means respectively.

Table 4: Analysis of Variance for SN ratios.

\begin{tabular}{|l|c|c|c|c|c|c|}
\hline Source & DF & Seq SS & \multicolumn{1}{|l|}{ Adj SS } & Adj MS & F & P \\
\hline Shoulder Height & 4 & 7.2989 & 7.2989 & 1.8247 & 16.78 & 0.001 \\
\hline Arm Length & 4 & 1.1355 & 1.1355 & 0.2839 & 2.61 & 0.116 \\
\hline Table Width & 4 & 0.9279 & 0.9279 & 0.2320 & 2.13 & 0.168 \\
\hline Table Height & 4 & 5.2732 & 5.2732 & 1.3183 & 12.12 & 0.002 \\
\hline Residual Error & 8 & 0.8699 & 0.8699 & 0.1087 & & \\
\hline Total & 24 & 15.5054 & & & & \\
\hline
\end{tabular}

Hence the optimum design values for "smaller is better" are shoulder height as $1485 \mathrm{~mm}$, Arm length as $549 \mathrm{~mm}$, table width as $642 \mathrm{~mm}$ and table height as $920 \mathrm{~mm}$. To evaluate the optimized design Delmia V5 Ergonomics design and analysis module was used in which the table is designed according to the optimized table height and table width dimensions and the manikins of $5^{\text {th }}, 25^{\text {th }}, 50^{\text {th }}, 75^{\text {th }}$ and $95^{\text {th }}$ percentile are used respectively for ergonomic analysis.

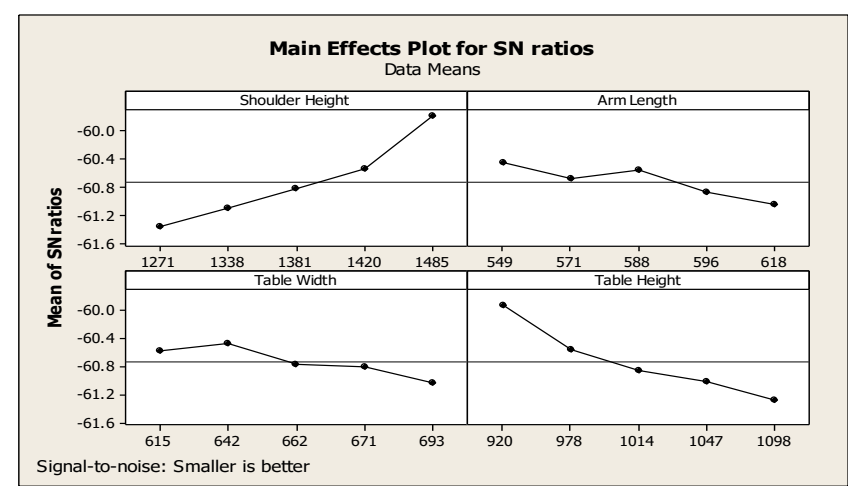

Fig. 2: Main Effect Plot for SN ratios. 


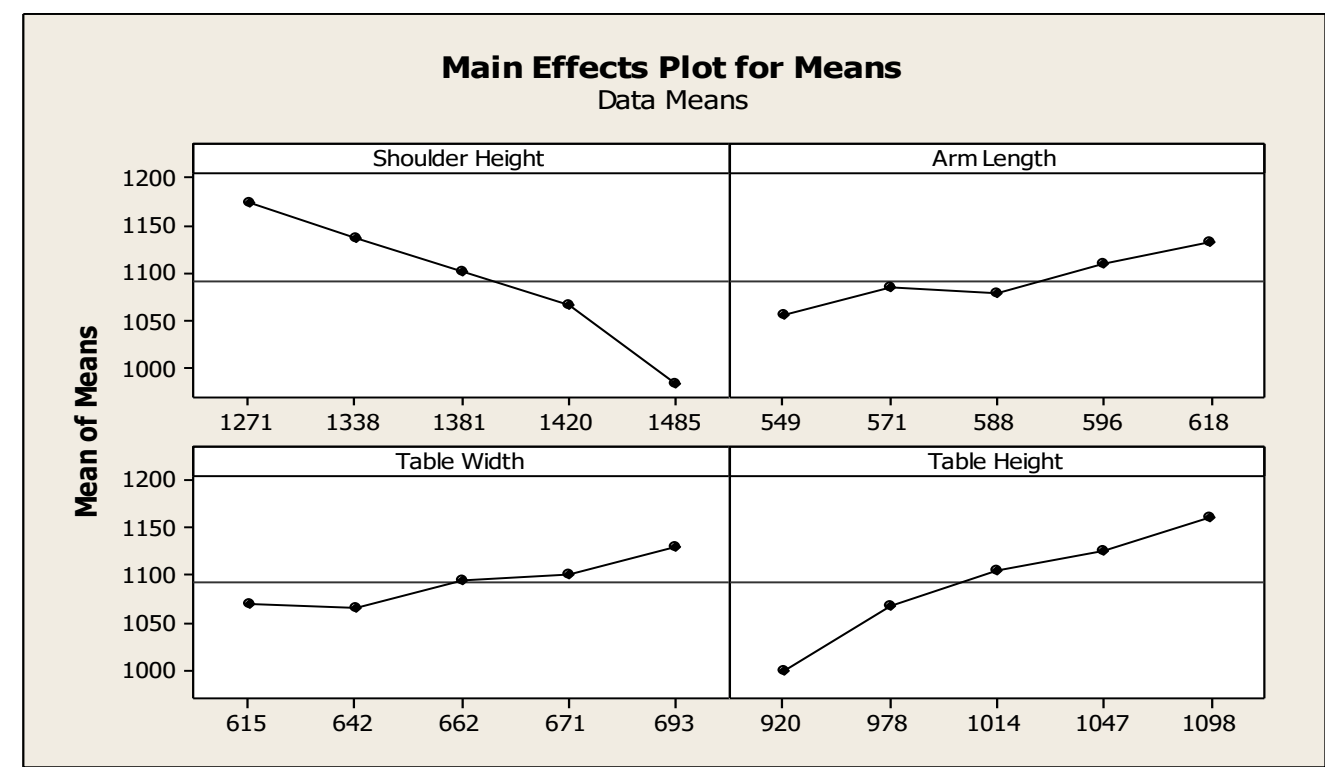

Fig. 3: Main Effect Plot for Means.

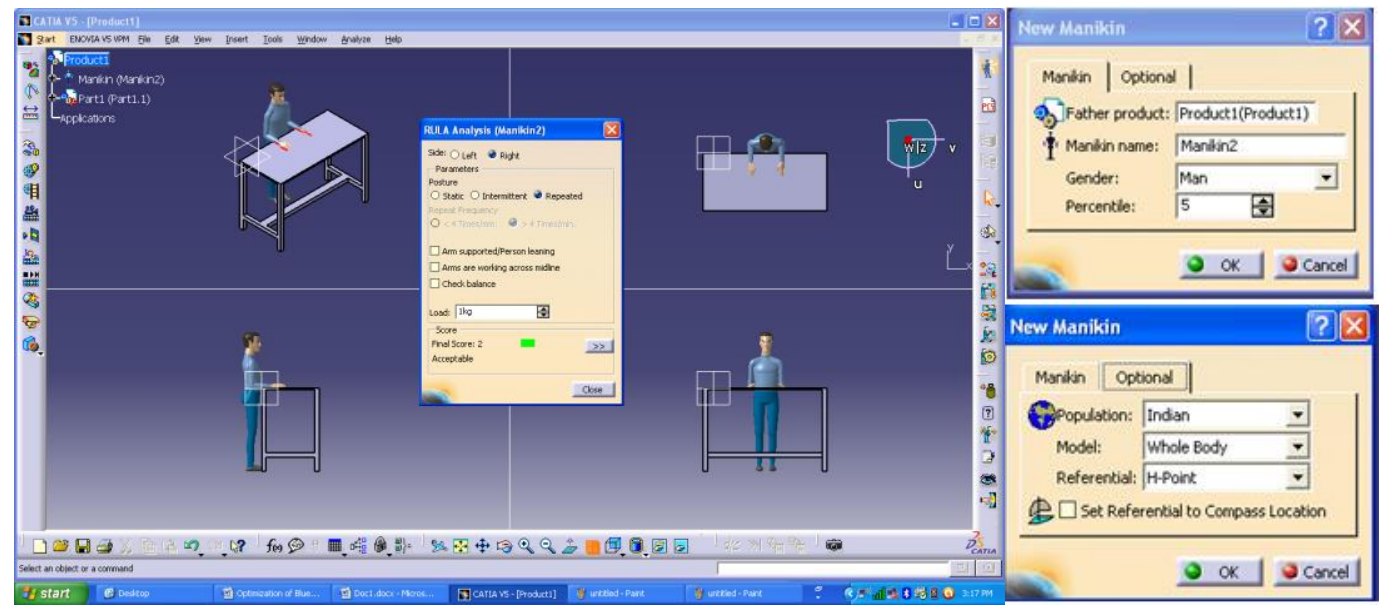

Fig. 4: Manikin of $5^{\text {th }}$ percentile of Indian population on optimized working table with RULA score.
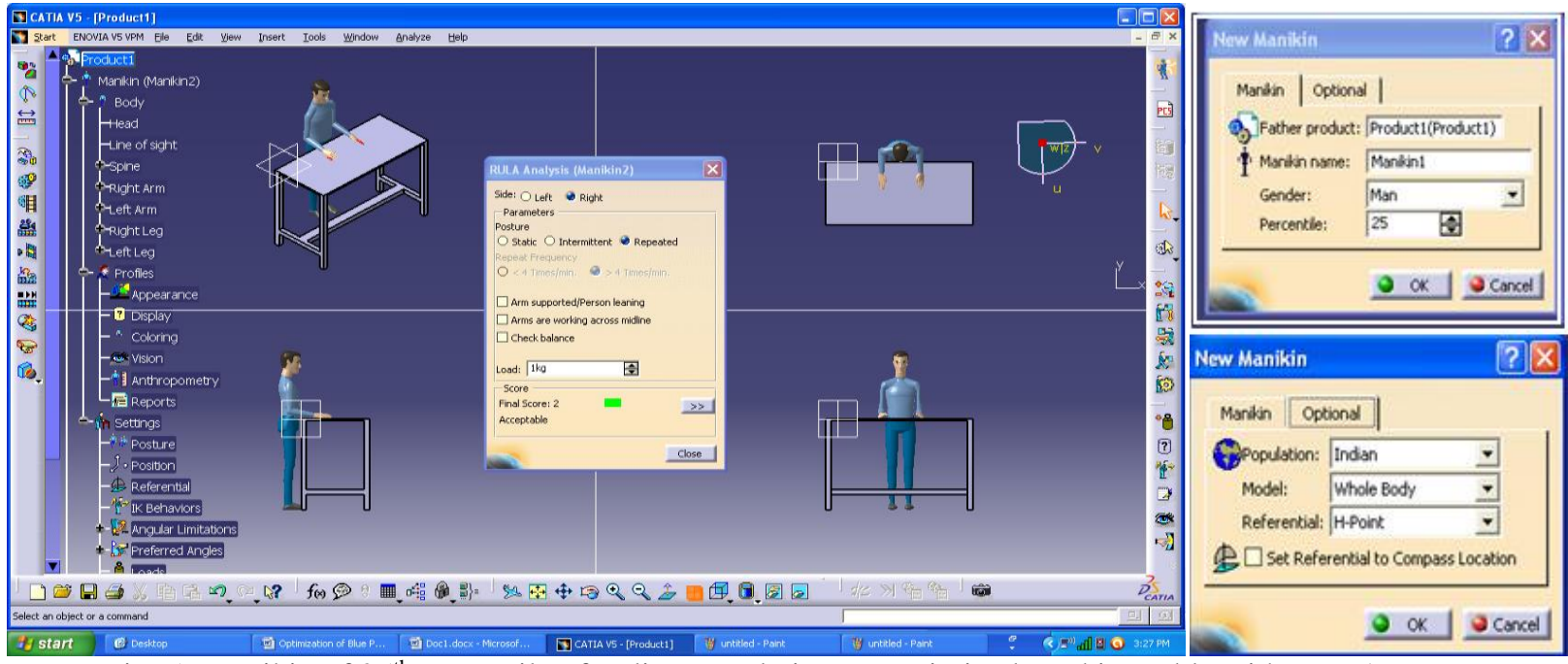

Fig. 5: Manikin of $25^{\text {th }}$ percentile of Indian population on optimized working table with RULA score. 


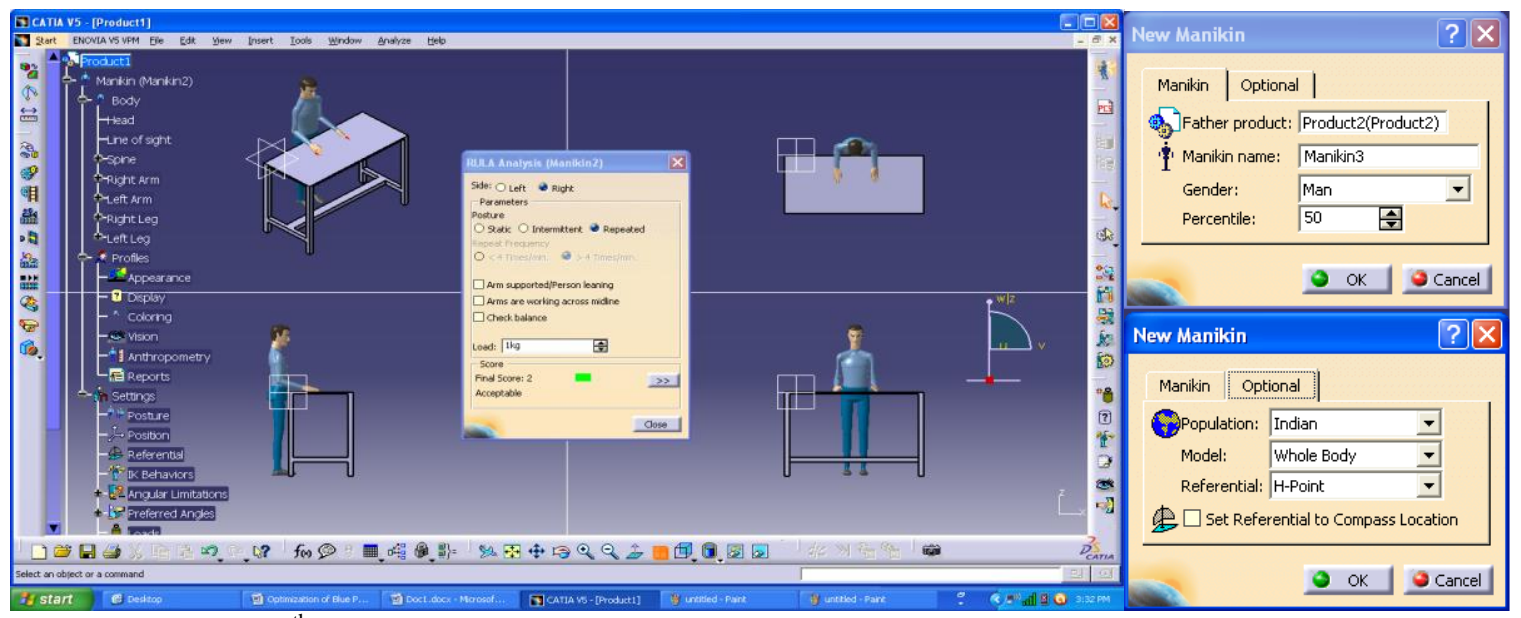

Fig. 6: Manikin of $50^{\text {th }}$ percentile of Indian population on optimized working table with RULA score manikin.

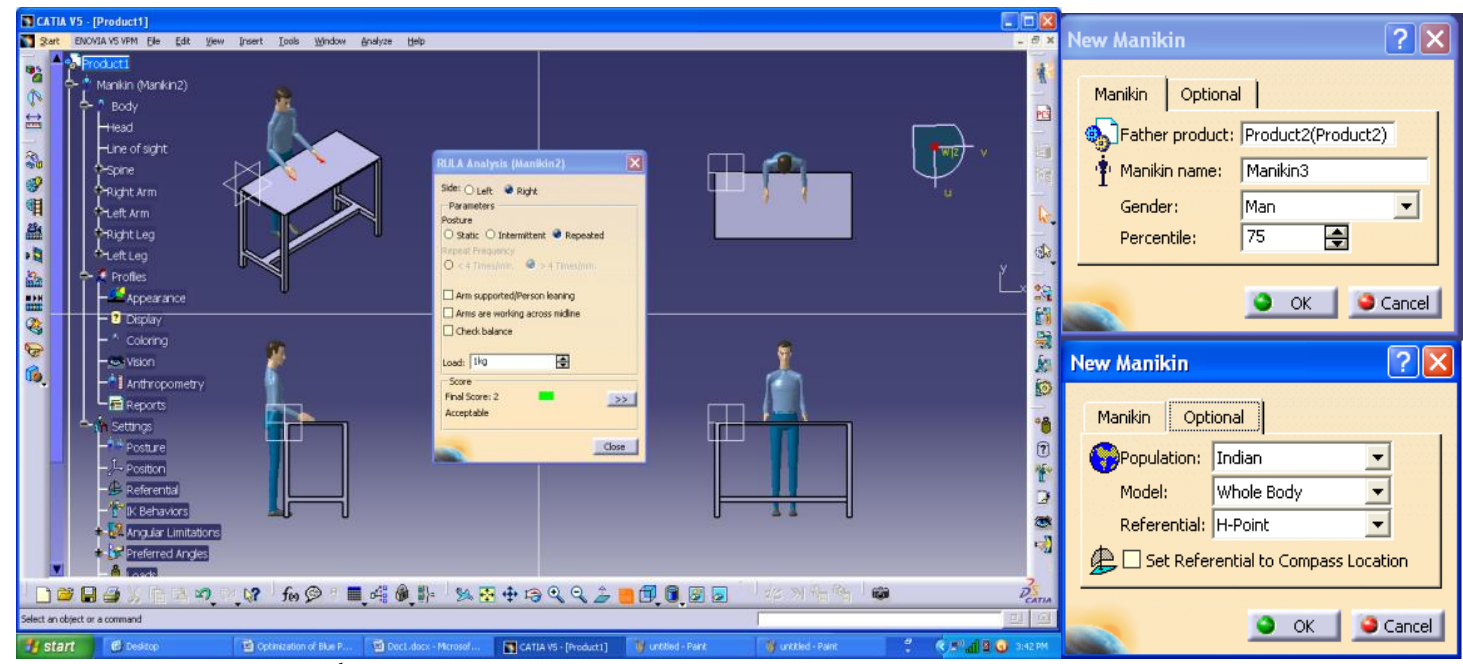

Fig. 7: Manikin of $75^{\text {th }}$ percentile of Indian population on optimized working table with RULA score.

Figure (4) to figure (8) shows the ergonomic posture (RULA) analysis of $5^{\text {th }}, 25^{\text {th }}, 50$ th $75^{\text {th }}$ and $95^{\text {th }}$ percentile manikin of Indian population anthropometry. RULA [6] analysis shows that the scores of two (2) (Accepted) are same for five different levels of anthropometry.

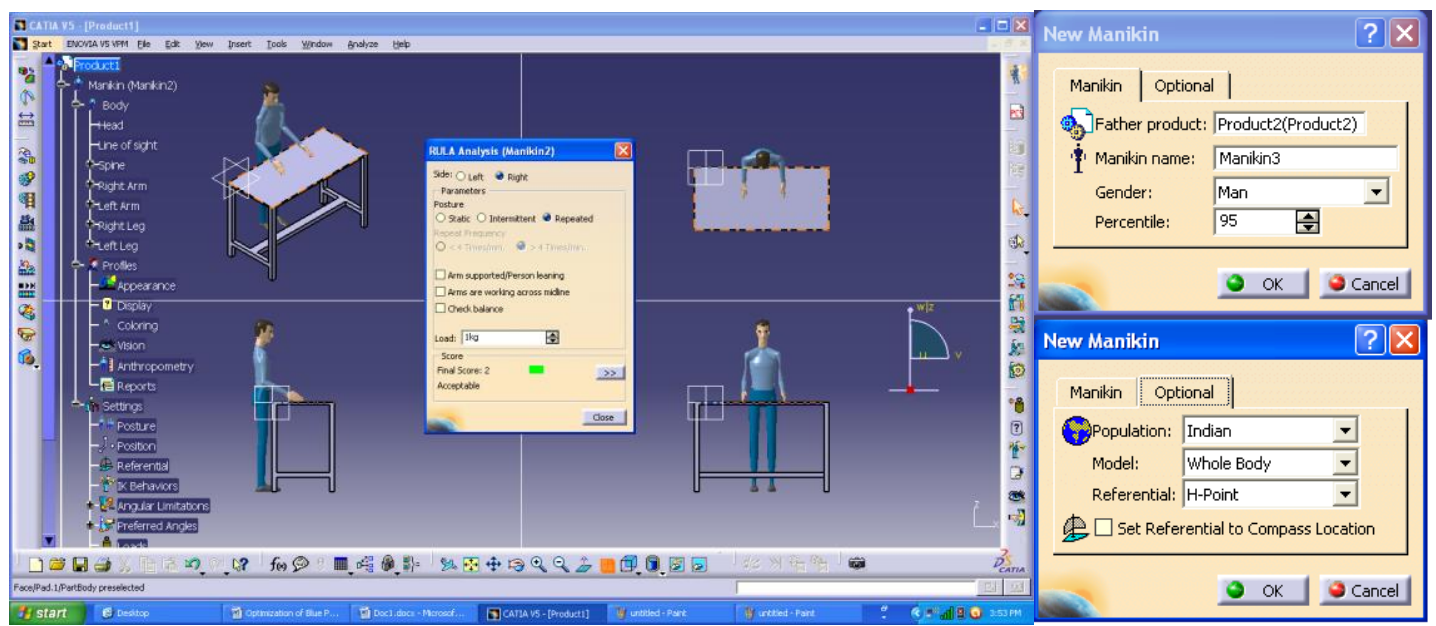

Fig. 8: Manikin of $95^{\text {th }}$ percentile of Indian population on optimized working table with RULA score. 


\section{Conclusion}

An ergonomic work table was designed using Taguchi's Design of experiment approach and the optimized dimensions of table height and width are $920 \mathrm{~mm}$ and $642 \mathrm{~mm}$ respectively. The designed work table was evaluated using Ergonomics Design and analysis module of Delmia V5 software. The RULA scores for 5 levels of anthropometry are two (2) which indicate the posture is accepted. Even though the scores are same but for the $5^{\text {th }}$ and $25^{\text {th }}$ population there is raise in shoulders however this problem can be solved by using a platform of $100 \mathrm{~mm}$.

\section{References}

[1] P. W. Buckle and D. A. Stubbs, "Epidemiological aspects of musculoskeletal disorders of the shoulder and upper limbs," in: Contemprary Ergonomics, E. J. Ed., Taylor \& Francis, London, pp 75-78. 1990.

[2] A. Aarås, R. H. Westgaard, E. Stranden, "Postural angles as an indicator of postural load and muscular injury in occupational work situations," Ergonomics, vol. 31, pp. 915-33, 1988.

[3] P. Mukhopadhyay and S. Srivastava, "Ergonomics risk factors in some craft sectors of Jaipur," HFESA Journal Ergonomics Australia, vol. 24, no. 1, pp. 4-14, 2010.

[4] E. N. Corlett and R. P. Bishop, “A technique for assessing postural discomfort," Ergonomics, vol. 19, no. 12, pp. 175 $182,1976$.

[5] Somasundaram \& Srinivasan, "Design Optimization of Dosa Making Workstation," Journal of Scientific \& Industrial Research, vol. 69, 2010.

[6] L. McAtamney \& E. N. Corlett, "RULA: A survey for the investigation of work-related upper limb disorders," Applied Ergonomics, vol. 24, pp. 91-99, 1993. 